\title{
An Analysis of the Relationship between Air Pollutants and Urban Characteristics using the Trajectory Model: The case of Seoul, Korea
}

\author{
Sangheon Lee and Kyushik Oh
}

\begin{abstract}
In Korea, there have been a number of efforts to resolve environmental problems which are caused by rapid urbanization, industrialization, and excessive concentrations of the population. As a result of these efforts, various environmental problems have been mitigated. However, the air pollutant, $\mathrm{NO}_{2}$, is still difficult to control in major cities such as Seoul, the capital of Korea, due to continuous increases of traffic volume and energy use. For more effective management of $\mathrm{NO}_{2}$, the emission volume of air pollutants needs to be controlled. Therefore, in this study the location and emission volume of air pollutant sources were identified by using a trajectory model that conversely applies the air dispersion process. The simulation results of the trajectory model were sorted by 'seasonal' and 'hourly', and the relationship between the air pollutants' emission and spatial characteristics such as density, landuse, and traffic volume were identified. The results of this study show that the emission of $\mathrm{NO}_{2}$ is mainly influenced by the variables of naturalness, land-uses, and the intensity of human activities. In particular, this research shows that industrial land-use and main roads have a considerable impact on $\mathrm{NO}_{2}$ emission. Therefore, the allocation of land-use and traffic volume needs to be considered in the process of urban planning and management to improve air quality.
\end{abstract}

Index Terms-Air pollutant, emission volume, trajectory model, urban characteristics

\section{INTRODUCTION}

Due to development-oriented growth and change in the industrial structure of the 1960s, environmental quality had been rapidly worsening in Seoul, the capital of Korea. Most of these environmental problems have been resolved with the implementation of environmental pollutants policies and management. Among the types of environmental pollution, air quality, which has a direct impact on human health, has been markedly improving due to various efforts including the introduction of clean energy. Subsequently, atmospheric pollutants that include $\mathrm{SO}_{x}, \mathrm{CO}$ and $\mathrm{O}_{3}$ concentrations are now being maintained under national standards. On the other hand, $\mathrm{NO}_{2}$ levels still need to be managed intensively. However, the management of air pollution is not simple, because of the criteria which are used in studies or for policy suggestions are limited to concentrations and emission volume of air pollutants.

With the concentrations and emission volume of air pollutants that are currently used, it is difficult to determine

Manuscript received September 13, 2012; revised October 25, 2012.

The authors are with Department of Urban Planning, Hanyang University, 222 Wangsimni-ro, Seongdong-gu, Seoul 133-791, Korea (e-mail: shlee0901@gmail.com; ksoh@ hanyang.ac.kr). the exact source location and emission volume of the air pollutants. Because concentrations are the result of dispersion influenced by weather conditions and topography, the emission volume is simply calculated by the coefficient derived from a statistics database. To cope with such pollution problems, the trajectory model can be adopted to deduce the location of an air pollutant source and the emission volume. In this study, the trajectory model, which is frequently used in atmospheric science, was adopted to a real urban space to analyze the spatial characteristics of air pollutant emissions. Then methods to consider the air quality in the process of urban planning and management were suggested.

\section{LITERATURE REVIEW}

\section{A. The Relationship between Air Pollution and Urban Characteristics}

Air quality is determined by air pollutants which are emitted from human activities. Therefore, managing human activities is essential for improving air quality rather than attempting to remove just air pollutants themselves.

One of the studies that analyzed the relationship between the emission of air pollutants and urban characteristics was conducted by Ricaby (1991) [1]. In this study, the effect of land-use and traffic patterns on air pollution was analyzed with the study area of British cities. Moreover, Lin's (2002) study showing the effect of linear sources of air pollutants and traffic volume on air pollution was analyzed [2]. Puliafito (2003) researched the actual conditions of air pollution in cities with the measured information of weather and pollution [3].

\section{B. Trajectory Model}

Brankov et al. (1997) used the trajectory model, which can derive the paths of air pollutants in a specific period, to find out potential sources [4]. It operates the traditional dispersion model inversely to find out the source location and emission volume of air pollutants with consideration to creation and sink pattern (Apadula et Al., 2003) [5]. The trajectory model is usually used to trace the paths of $\mathrm{PM}_{10}$ and $\mathrm{CO}_{2}$ between continents but is scarcely adopted on the urban scale.

There are some methods to trace air pollutants. One involves the differences between real measured and simulated concentrations at each iteration (Tans et al., 1989; Conway et al., 1994; Masarie and Tans, 1995) [6]-[8]. Another method adopts statistical techniques to calculate the 
interaction among the grid cells that contain the concentration information. Then the location of the air pollutant source is derived (Ashbaugh, 1983; Ashbaugh et al., 1985; Seibert et al., 1994; Stohl, 1996) [9], [10], [11], [12].

\section{Methods}

\section{A. Trajectory Model}

The concentration of air pollutants is the result of the dispersed air pollutants by wind. Therefore, if the reverse effect of wind direction, wind speed, and topography of the concentration is calculated, the location and emission volume of the air pollutants can be derived. The result of the trajectory model is more accurate with more sensors that measure weather conditions and concentrations, and with shorter target times (near past) because this is based on the air dispersion model. The concept of the trajectory model is shown in Fig.1.

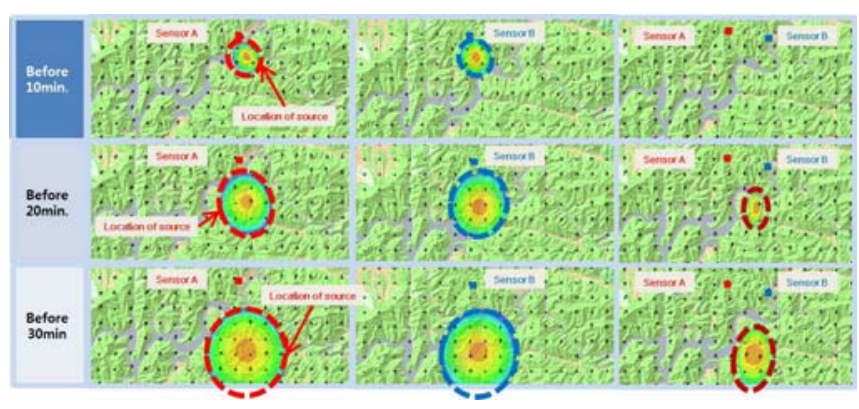

Fig. 1. Concept of trajectory modeling.

To ensure accuracy of the simulation, the trajectory model repeatedly simulations for 3 minutes again and again. As a result, there were 20 results of the simulation used to present the situation of 1 hour before, for example. Then, the cumulative results were analyzed to derive the location of the air pollutant sources and emission volume (see Fig. 2).

$\bar{e}=\frac{e_{1}+e_{2}+e_{3}+\cdots+e_{22}+e_{23}+e_{24}}{24}$

$\bar{e}$ : average emission volume

$e_{n}:$ emission volume at nth time iteration
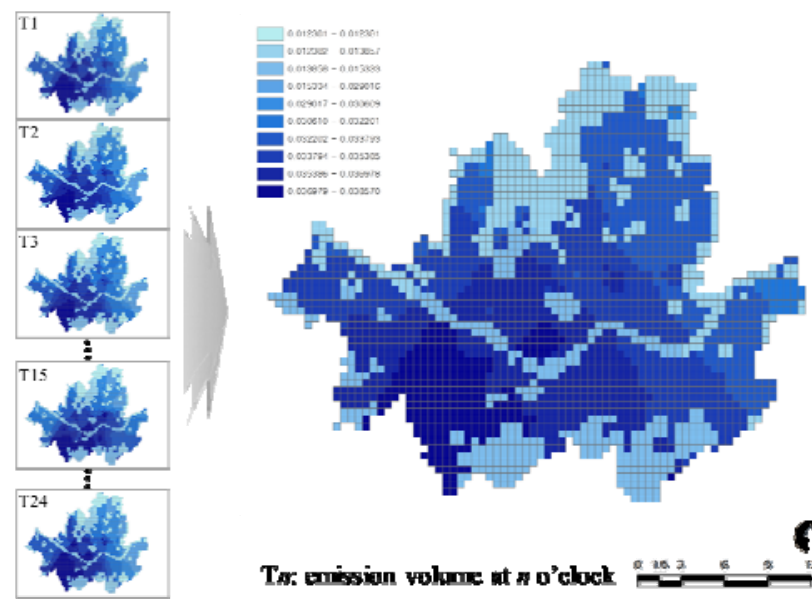

9

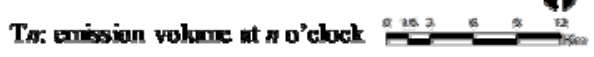

Fig. 2. Calculation of average emission of 1 day (24 hours).

\section{B. Variables Affecting Atmospheric Pollutant Emission}

The air pollutants being managed in Korea are $\mathrm{CO}, \mathrm{SO}_{2}$, $\mathrm{NO}_{2}$, and $\mathrm{PM}_{10}$. Among these, the concentrations of $\mathrm{CO}$ and $\mathrm{SO}_{2}$ have been kept under the legal standard. However $\mathrm{NO}_{2}$ and $\mathrm{PM}_{10}$ are still difficult to manage. $\mathrm{PM}_{10}$ is difficult to control because of the spring season during which yellow dust arrives from China, and from its generation from various construction projects. Moreover, the characteristics of $\mathrm{PM}_{10}$ that are formed and dissipate in the air by chemical reactions make them unsuitable to apply to the trajectory model. Therefore, $\mathrm{NO}_{2}$ is the main target variable applied to the trajectory model in this study.

Furthermore, because the emission of air pollutants is related to human activities, the variables which have an effect on $\mathrm{NO}_{2}$ emissions were selected from the categories of naturalness, land-use, and intensity of human activities, all of which can explain the types and intensities of human activities in urban spaces (see Table I).

TABLE I: VARIABLEs AfFecting ATMOSPHERIC POLLUTANT EMISSION

\begin{tabular}{c|c|c}
\hline \hline Classification & Variables & Units \\
\hline \multirow{4}{*}{ Naturalness } & Slope & $\%$ \\
\cline { 2 - 3 } & Altitude & $\mathrm{m}^{2}$ \\
\cline { 2 - 3 } & Areas of water & $\mathrm{m}^{2}$ \\
\hline \multirow{4}{*}{ Land-use } & Areas of green space & $\mathrm{m}^{2}$ \\
\cline { 2 - 3 } & Areas of residential districts & $\mathrm{m}^{2}$ \\
\cline { 2 - 3 } & Areas of industrial districts & $\mathrm{m}^{2}$ \\
\cline { 2 - 3 } & Areas of commercial & $\mathrm{m}^{2}$ \\
\cline { 2 - 3 } & and business districts & $\mathrm{m}^{2}$ \\
\cline { 2 - 3 } Intensity of & Areas of roads & $\mathrm{m}^{2}$ \\
\cline { 2 - 3 } human activities & Building coverage ratio (BCR) & $\%$ \\
\cline { 2 - 3 } & Floor area ratio (FAR) & persons/ha \\
\cline { 2 - 3 } & Traffic volume & vehicles \\
\hline \hline
\end{tabular}

\section{Data Establishment}

The concentration of air pollutants, weather conditions including wind speed, wind direction and temperature, and the topography which have an effect on the wind flow, need to be inputted to operate the trajectory model. Such information except for topography is gatherable from air pollution sensors which are being operated by the government. The air pollution sensors measure concentrations of $\mathrm{SO}_{2}, \mathrm{NO}_{2}, \mathrm{CO}, \mathrm{PM}_{10}$, and weather conditions including wind direction, wind speed, and temperature at intervals of one hour.

In this study, a total of 32 sensors were used as input data. Of them, 23 are in Seoul which measure the concentrations of inner Seoul, and the remaining 9 sensors are located around Seoul and are used to reflect the flow of air pollutants from outside of Seoul. The data of spring and fall were analyzed to reveal the spatial patterns of air pollutant emissions. This is because the result of the trajectory model of summer or winter could be less correct due to the effects of rain, snow, moisture, and strong wind. Therefore, two days, one from spring and the other from fall, which showed representative weather conditions (wind direction, wind speed, and temperature with no rain) were selected as input data in this 
study.

\section{CASE STUdY}

\section{A. The Study Area}

The trajectory model was applied to Seoul, the capital of Korea (see Fig. 3). Seoul is one of the densest cities in the world in which $21.5 \%$ of the country's total population reside within $0.6 \%$ of land area. Therefore, Seoul is vulnerable to atmospheric pollution and the air quality needs to be managed continuously. The study area that was analyzed extends to the location of the air pollution sensors and those near Seoul.

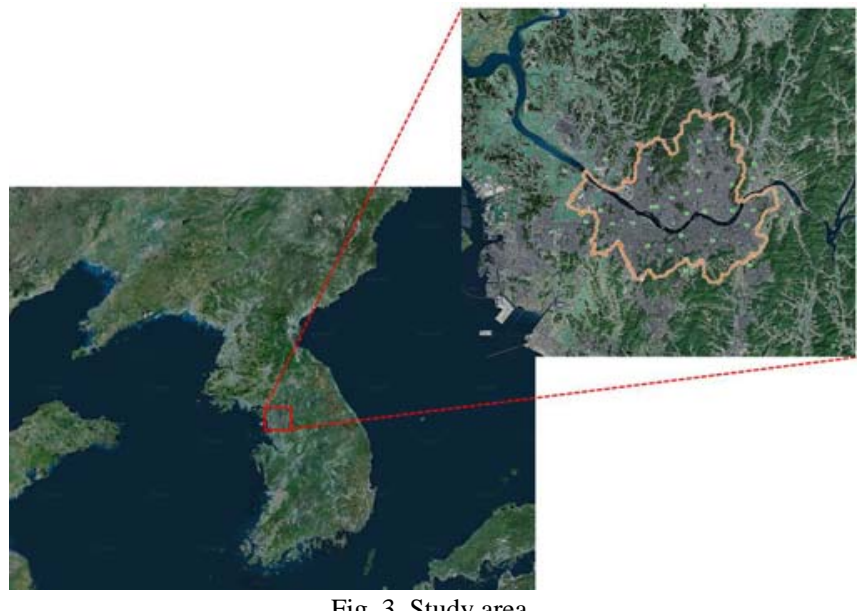

\section{B. Results of Correlation Analysis}

The emission volume that was derived by the trajectory model is expressed in grid cells with the resolution of $500 \mathrm{~m} \mathrm{x}$ $500 \mathrm{~m}$. Each cell has the variables of naturalness, land-use, and intensity of human activities in order to determine the factors that influence the emission volume. The results of correlation analysis show that every variable is significant and most of them have a strong correlation coefficient regardless of season (see Table II).

The variables of naturalness show a negative correlation because slope, altitude, greens, and water limit development or human activities. In the case of land-use, residential, commercial-business, and traffic, there is a positive and strong correlation. Industrial land-use, which is commonly thought to generate much air pollutant emission, shows a weaker correlation than other land-uses. This is because most industrial zones consist of semi-industries rather than heavy industries, and the total area is much smaller than other land-uses. In addition, a strong positive correlation (0.440 0.572 ) is shown in the population density, building coverage ratio, floor area ratio, and traffic volume and represents the intensity of human activities.

\section{Seasonal Emission Volume}

The average emission volume of each season shows a similar tendency regardless of the seasonal difference. In Fig. 4, the southwestern part (A) shows the highest emission volume where the main industrial zone exists in Seoul. Meanwhile (B) and (C) are the CBD (Central Business District) of Seoul where the commercial and business zones are located with high densities, and subsequently there is high emission volume. Moreover, (D) indicates old residential areas, but has high traffic volume because a major road passes through the area and a train depot is located there. In the (F) area, there is a steam power plant so $\mathrm{NO}_{2}$ is emitted heavily. As shown in Fig. 4, there is low emission volume around Seoul. This is because there is a greenbelt where urban development and human activities are restricted.

TABLE II: RESULT OF CORRELATION ANALYSIS

\begin{tabular}{|c|c|c|c|c|c|c|c|c|c|c|c|c|c|}
\hline & Slope & Altitude & Water & Greens & Residential & Public & Industrial & $\begin{array}{c}\text { Commercial } \\
\& \\
\text { Business } \\
\end{array}$ & Roads & $\begin{array}{c}\text { Population } \\
\text { density }\end{array}$ & BCR & FAR & $\begin{array}{l}\text { Traffic } \\
\text { volume }\end{array}$ \\
\hline \multirow{2}{*}{ Spring } & -.542 & -.513 & -.199 & -.682 & .397 & .210 & .122 & .303 & .648 & .440 & .569 & .525 & .505 \\
\hline & .000 & .000 & .000 & .000 & .000 & .000 & .000 & .000 & .000 & .000 & .000 & .000 & .000 \\
\hline \multirow{2}{*}{ Fall } & -.533 & -.511 & -.198 & -.682 & .392 & .210 & .129 & .309 & .652 & .440 & .572 & .531 & .505 \\
\hline & .000 & .000 & .000 & .000 & .000 & .000 & .000 & .000 & .000 & .000 & .000 & .000 & .000 \\
\hline
\end{tabular}
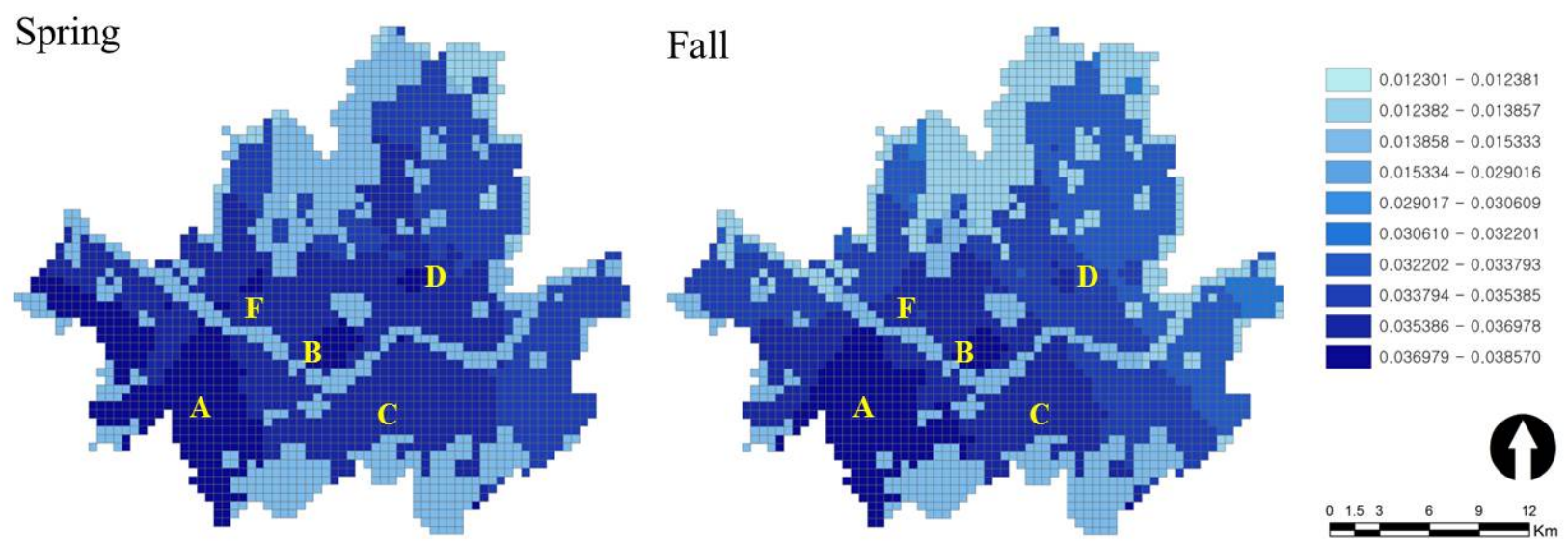

Fig. 4. Seasonal emissions (unit: ton/hour·cell). 


\section{Spring}

Morning Rush hour (7A.M. - 9 A.M.)

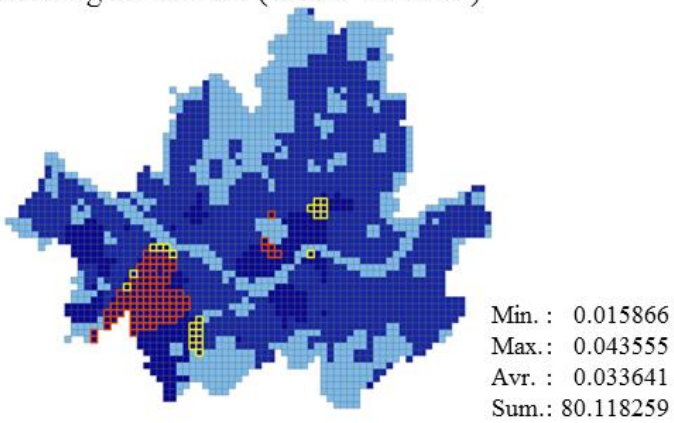

Fall

Morning Rush hour (7A.M. - 9 A.M.)

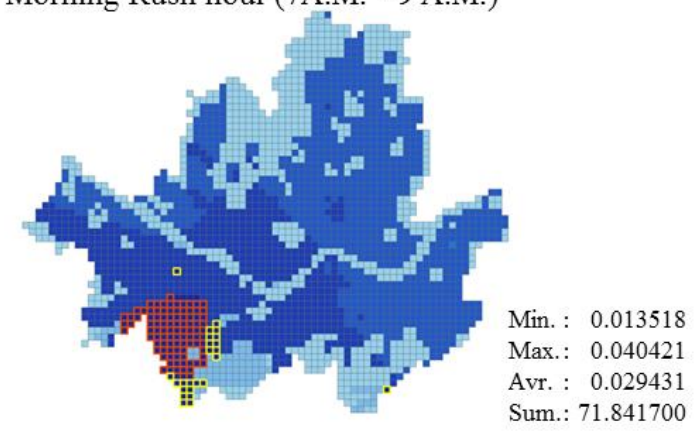

Business hour (9A.M. - 6 P.M.)

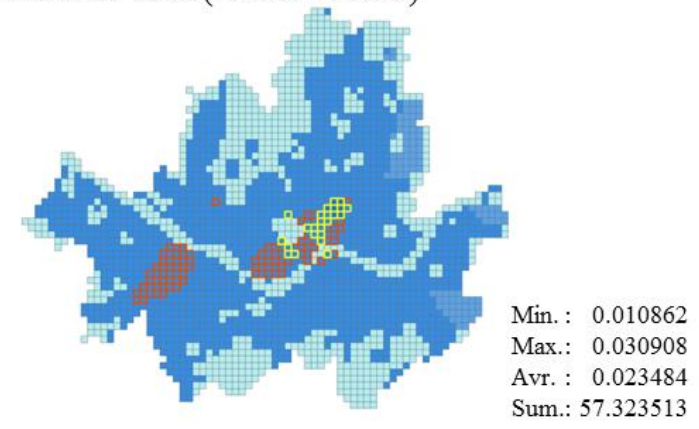

Business hour (9A.M. - 6 P.M.)

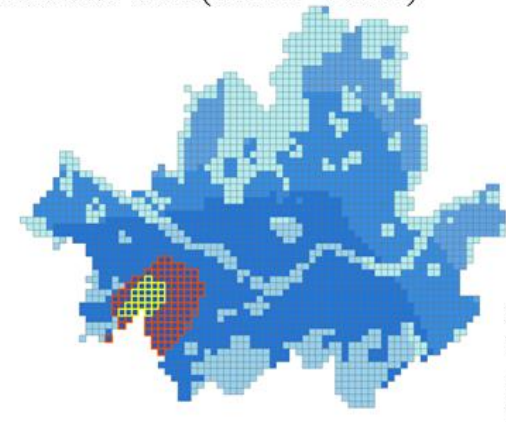

Min. : 0.009705

Max.: 0.034204

Avr. : 0.024576

Sum.: 59.991126
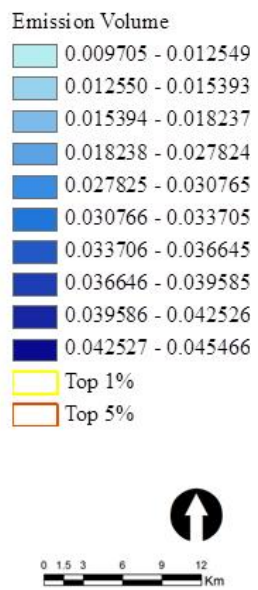

Fig. 5. Temporal emissions (unit: ton/hour·cell).

\section{Temporal Emission Volume}

Human activities are different depending on the time, and this has a sequential effect on the emission of air pollutants. For example, the emission volume might be dominant in traffic areas during rush hour when most people commute, while there might be high emission volume in the business and industrial areas during business hours. Hence, the temporal differences among emission volumes were analyzed in this study, and the results are shown in Fig. 5.

During rush hour in the morning, the emission volume is high in the southern part of Seoul, where there are main roads to exit and enter Seoul. Needless to say, there is heavy traffic volume because many people commute from outside of Seoul. Meanwhile, there is high emission volume during business hours in the southwestern part of the city where the industrial zone and CBD are situated.

A similar tendency is shown in fall. However, there is much more emission volume in the main industrial zone than in the CBD during business hours.

The total emission volume at each time slot, which indicates the sum of emission volumes of all cells at rush hour in the morning and business hours, shows that there is more emission volume during rush hour than during business hours. This means the emission of $\mathrm{NO}_{2}$ is dominate in the traffic areas.

\section{CONCLUSION}

The source location of air pollutants and emission volume can be derived by using the emission factor or actual measurements. However, the emission factor is insufficient in terms of accuracy because it is a statistically generalized value so it is not able to calculate the actual and exact emission volume. Meanwhile another method involving the use of actual measurements is the most precise if the expenses to set up a large number of sensors and the operation of the sensors are not considered. Therefore, in terms of balance between accuracy and economical efficiency, the use of the trajectory model is most useful.

In this study, the trajectory model was applied to urban spaces to determine the location of air pollutant sources and the emission volume at each source with the data set of $\mathrm{NO}_{2}$ concentrations measured by sensors. To execute the inverse process of the traditional dispersion model, wind speed and direction, temperature, and topography were used as input data. Then, the simulation results of the trajectory model were sorted seasonally and temporally.

The result of the trajectory model makes it possible to regulate the emission sources directly, and this can lead to suggestions for fundamental solutions to improve air quality in urban areas. For instance, measurements to reduce emissions can be taken where there are air pollution sources. And in terms of planning and management, high density development can be restricted, or wind corridors and green spaces can be created to lessen the concentration of air pollutants by dispersion and absorption.

Moreover, the result of the trajectory model can be applied to the urban planning process. This in turn can lead to a balance between development and environmental soundness, and ultimately, improvement in the life quality for citizens.

\section{ACKNOWLEDGMENT}

This research was supported by a grant (07High Tech A01) from the High tech Urban Development Program funded by 
the Ministry of Land, Transportation and Maritime Affairs of the Korean government.

\section{REFERENCES}

[1] P. Ricaby, "Energy and urban development in and archetypal English town," Environment and Planning B, vol. 14, pp. 139-223, 1989.

[2] Lin, "The application of GIS to air quality analysis in Taichung City, Taiwan ROC," Environmental Modelling \& Software, vol. 17, 2002.

[3] E. Puliafito, M. Guevara, and C. Puliafito, "Characterization of urban air quality using GIS as a management system," Environmental Pollution, vol. 122, no. 1, pp. 105-117, 2003.

[4] E. Brankov, S. Rao, and P. Porter, "A trajectory-clustering-correlation methodology for examining the long-range transport of air pollutants," Atmospheric Environment, vol. 32, pp. 1525-1524, 1997.

[5] F. Apadula, A. Gotti, A. Pigini, A. Longhetto, F. Rocchetti, C. Cassardo, S. Ferrarese, and R. Forza, "Localization of source and sink regions of carbon dioxide through the method of the synoptic air trajectory statistics,” Atmospheric Environment, vol. 37, pp. 3757-3770, 2003.

[6] T. Conway, P. Tans, L. Waterman, K. Thoning, D. Kitzis, K. Masarie, and N. Zhang, "Evidence for interannual variability of the carbon cycle from the National Oceanic and Atmospheric Administration/Climate
Monitoring and Daignostic Laboratory Global Air Sampling Network,” Journal of Geophysical Research, vol. 99, pp. 22831-22855, 1994.

[7] K. Masarie and P. Tans, "Extension and integration of atmospheric carbon dioxide data into a globally consistent measurement record," Journal of Geophysical Research, vol. 100, pp. 11593-11610, 1995.

[8] P. Tans, T. Conway, and T. Nakazawa, "Latitudinal distribution of the sources and sinks of atmospheric carbon dioxide derived from surface abservations and atmospheric transport model," Journal of Geophysical Research, vol. 94, pp. 5151-5172, 1989.

[9] L. Ashbaugh, "A statistical trajectories technique for determining air pollutant source region," Journal of the Air pollutant Control Association, vol. 33, pp. 1096-1098, 1983.

[10] L. Ashbaugh, W. Malm, and W. Sadeh, "A residence time probability analysis of sulfur concentrations at grand Canyon National Park," Atmospheric Environment, vol. 19, no. 8, pp. 1263-1270, 1985.

[11] P. Seibert, H. Kromp-Kolb, U. Baltensperger, D. Jost, M. Schwikowsdi, A. Kasper, and H. Puxbaum, "Trajectory analysis of aerosol measurements at high Alpine sites. In: Borell, P.M., Cvitas, T., Seiler, W. (Dds.)," Transport and Transformation of Pollutants in the Troposphere. Academic Publishing, Den Haag, pp. 689-693, 1994.

[12] A. STOHL, "Trajectory statistics-a new method to establish source-receptor relationship of air pollutants and its application to the transport of particulate sulphate in Europe," Atmospheric Environment, vol. 30, pp. 579-587, 1996 